\title{
Hispidin attenuates bleomycin-induced idiopathic pulmonary fibrosis via an anti-oxidative effect in A549 cells
}

\author{
Chen-Xi Ren ${ }^{1 \dagger}$, Xin Jin ${ }^{2 \dagger}$, Dan-Ping Xie ${ }^{1}$, Xiao-Yu Guo ${ }^{1}$, Li-Yun Yu' ${ }^{1}$,Yu-Dong Cui ${ }^{*}$, Taeho Kwon ${ }^{3 *}$ (I) and \\ Hu-Nan Sun ${ }^{1 *}$
}

\begin{abstract}
Idiopathic pulmonary fibrosis (IPF) is a serious and irreversible chronic lung disease. Bleomycin (BLM) is an anticancer drug, which can cause severe lung toxicity. The main target of oxidative stress-induced lung injury is alveolar epithelial cells, which lead to interstitial fibrosis. The present study investigated whether hispidin (HP), which has excellent antioxidant activity, attenuates bleomycin-induced pulmonary fibrosis via anti-oxidative effects in A549 cells. We found that hispidin reduced bleomycin-induced fibrosis of A549 cells by reducing reactive oxygen species (ROS) levels and inhibiting epithelial-mesenchymal transition. Taken together, our data suggest that hispidin has therapeutic potential in preventing bleomycin-induced pulmonary fibrosis.
\end{abstract}

Keywords: Bleomycin, Epithelial-mesenchymal transition, Hispidin, Idiopathic pulmonary fibrosis, Reactive oxygen species

\section{Introduction}

Idiopathic pulmonary fibrosis (IPF) is a serious and irreversible chronic lung disease [1]. IPF has the following characteristics: Excessive accumulation of fibroblasts, extensive deposition of the extracellular matrix, alveolar structure damage, and a gradual decline of lung function [2]. Smoking, sawdust, sand, and silica exposure may lead to repeated injury of alveolar epithelial cells. Many studies have shown that injury and apoptosis of alveolar epithelial type II cells are important early features of IPF [3]. IPF is accompanied by epithelial cell apoptosis, epithelial-mesenchymal transition (EMT) and matrix

\footnotetext{
*Correspondence: cuiyudong@126.com; kwon@kribb.re.kr; sunhunan76@163.com

${ }^{+}$Chen-Xi Ren and Xin Jin contributed equally to this work

${ }^{1}$ College of Life Science \& Technology, Heilongjiang Bayi Agricultural University, Xinyanglu, 163319 Daqing, People's Republic of China

${ }^{3}$ Primate Resources Center, Korea Research Institute of Bioscience and Biotechnology (KRIBB), 351-33 Neongme-gil, Ibam-myeon,

Jeongeup-si, Jeonbuk 56216, Republic of Korea

Full list of author information is available at the end of the article
}

metalloproteinase expression [4]. Oxidative stress is reportedly involved in the development of alveolar injury, inflammation, and fibrosis [5]. In recent years, the incidence rate of IPF has increased. Among the environmental factors, lung cell damage caused by inhalable particles and drug-induced interstitial lung disease have attracted extensive attention. For example, bleomycin-induced pulmonary fibrosis has become a serious clinical problem [6]. Nintedanib and pirfenidone are the only two antifibrotic drugs approved for the treatment of this disease worldwide, and both drugs can actively interfere with cellular redox state and oxidative stress $[7,8]$. However, all types of treatments failed to change the natural course of the disease, except for lung transplantation; therefore, a new and effective way of treatment is urgently required.

Bleomycin (BLM) is a complex glycopeptide with antitumor properties. It is often used as an antibiotic to treat various cancers in the clinic. Compared with other tissues, lungs lack the bleomycin-hydrolyzing enzyme. After bleomycin reaches the lung tissue, it leads to the production of reactive oxygen species (ROS) under the 
action of iron and oxygen, which increases oxidative stress, leading to severe pulmonary toxicity [9]. Oxidative stress is an important molecular mechanism, leading to fibrosis in many organs [10]. The main target of oxidative stress-induced lung injury is alveolar epithelial cells, which can lead to fibrosis [11]. The toxicity of BLM is directly caused by oxidative damage, and the production of intracellular ROS leads to inflammation and fibrosis [12]. The existing research shows that BLM causes the increase of ROS levels in A549 cells, which leads to oxidative stress in cells. In addition, BLM, through TGF- $\beta$ / Smad signaling pathway, induces EMT of A549 cells [13]. Many studies have shown that various plant extracts and active components have significant effects on inhibiting BLM-induced pulmonary fibrosis. Emodin alleviates BLM-induced pulmonary fibrosis in rats through antiinflammatory and antioxidant effects [14]. Submicron infusion of cinnamaldehyde improves BLM-induced IPF by inhibiting inflammation, oxidative stress and EMT [15]. Studies have shown that mitochondria play an important role in IPF [16]. Some studies suggest that ROS can promote EMT in certain types of cells [17] and mitochondrial ROS is the key factor of hypoxia-induced EMT in alveolar epithelial cells [18]. Here, we showed that HP significantly inhibited BLM-induced A549 fibrosis by reducing ROS levels, EMT, and mitochondrial membrane damage.

Hispidin (HP, 6-(3, 4-dihydroxystyryl)-4-hydroxy2-pyrone) and its derivatives are widely distributed in edible mushrooms, such as Lentinus edodes [19-21]. HP is extracted from Lentinus edodes, which is widely used to treat various diseases [16]. Most of these diseases are caused by the excessive production of free radicals, especially ROS. Studies have shown that HP can neutralize free radicals and is known for its strong anti-cancer, antioxidant, and DNA damage preventing activities [22]. It can also inhibit the growth and migration of tumors [23]. HP protects H9c2 cardiomyocytes from hydrogen peroxide-induced apoptosis by reducing ROS production and activation of Akt/GSK-3 $\beta$ and ERK1/2 signaling pathways $[24,25]$. At the same time, high concentration of HP can lead to high cytotoxicity and induce apoptosis [26]. HP can effectively protect min6n $\beta$ Cells from ROS damage [27], $C_{2} C_{12}$ myotubes from palmitate-induced oxidative stress [28], Caco-2 cells from acrylamide-induced oxidative stress [29], and ARPE-19 cells from hydrogen peroxide-induced damage by activating Nrf2 signaling and upregulating downstream targets, including phase II enzyme [30]. HP can prevent the damage caused by oxidative stress by scavenging ROS. Due to different effects of HP under different conditions, studying it further may help to treat cancer and prevent side effects caused by chemotherapy.
In light of the above-mentioned gaps in the field, this study aimed to explore the preventive and therapeutic effects of hispidin on pulmonary fibrosis.First, bleomycin was used to induce pulmonary fibrosis, and then A549 cells were pretreated with HP. MTT assay and would healing test were used to detect cell activity and cell migration, respectively, and western blotting was used to detect the expression of pulmonary fibrosis- and EMTrelated proteins. Flow cytometry and fluorescent microscopy were used to detect intracellular and mitochondrial ROS levels, as well as mitochondrial membrane potential. Our results will reveal the preventive and therapeutic effects of HP on fibrotic lung injury through anti-oxidation and anti-fibrosis activities.

\section{Material and methods}

\section{Reagents and antibodies}

A549 cell line was purchased from Daqing Hongtu Biotechnology Co., Ltd. (Heilongjiang, China). PBS and DMEM high glucose medium were purchased from Hyclone; TE/EDTA, penicillin/streptomycin, (P/S), and fetal bovine serum (FBS) from Solarbio; Hispidin (HP) from Shanghai Macklin Biochemical Co., Ltd. (Product No: H861853); dimethyl sulfoxide (DMSO) from Sigma; BLM from Gibco; 4,5-dimethylthiazol-2-yl)-2,5-diphenyltetrazolium bromide (MTT reagent from Amreso. All antibodies (anti- $\beta$-actin, anti- $\mathrm{N}$-cadherin, anti-E-cadherin, anti-vimentin, anti-fibronectin, and anti-slug) were purchased from Santa Cruz (CA, USA). Dihydroethidium (DHE), Mito-SOX, JC-1, and Hochest stains/probes were purchased from Solarbio.

\section{Cell culture}

A549 lung cancer cells were cultured in DMEM high glucose medium containing $10 \%$ inactivated FBS and $1 \% \mathrm{P} / \mathrm{S}$ in a humidified incubator with $5 \% \mathrm{CO}_{2}$. BLM $(200 \mu \mathrm{g} /$ $\mathrm{mL}$ ) and hispidin $(10,20$, or $30 \mu \mathrm{g} / \mathrm{mL}$ ) (Additional file 1; Fig. S1) were collectively administrated to the A549 cell line for $48 \mathrm{~h}$.

\section{Morphological observation}

Cells were seeded onto 24-well plates at a density of $6 \times 10^{3}$ cells/well. Serum-free DMEM was added and exposed to treatments accordingly. Images were acquired using an inverted microscope after $48 \mathrm{~h}$.

\section{MTT assay}

Cell morphology was observed under a light microscope. Cells were seeded onto 96-well plates at a density of $6 \times 10^{3}$ cells/well. Serum-free DMEM was added and treatments were performed accordingly. MTT solution (final concentration of $0.5 \mathrm{mg} / \mathrm{ml}$ in media) was then added to each well, and the plate was incubated at $37^{\circ} \mathrm{C}$ 
for an additional $4 \mathrm{~h}$. After removing all medium in each well, $100 \mu \mathrm{l}$ of DMSO was added to each well and the optical density was measured at $490 \mathrm{~nm}$.

\section{Wound healing assay}

Cells were seeded onto 24-well plates at a density of $2 \times 10^{5}$ cells/well. A scratch was established after the cells adhered to the plate. Then, the medium was removed and cells were washed with PBS three times. Serumfree DMEM was added and treatments were performed accordingly. Images were acquired using an inverted microscope after 0 and $48 \mathrm{~h}$. Image J software was used to calculate the scratch area as follows: Area healing $(\%)=[($ average gap at $0 \mathrm{~h}$-average gap at $48 \mathrm{~h}) /$ average gap at $0 \mathrm{~h}] \times 100 \%$.

\section{Fluorescence microscopy}

The superoxide anion in mitochondria and mitochondrial membrane potential were measured using the fluorescent probe MitoSOX/JC-1 and Hoechst dye. Cells were seeded onto 24-well plates at a density of $6 \times 10^{4}$ cells/well. Serum-free DMEM was added and treatments were performed accordingly. Followed by washing twice with PBS, the cells were incubated with the fluorescent probe MitoSOX/JC-1 and Hoechst dye for $15 \mathrm{~min}$ at $37{ }^{\circ} \mathrm{C}$. After the reaction, cells were washed twice with PBS and the superoxide anion in mitochondria, as well as the mitochondrial membrane potential, were detected using an inverted fluorescence microscope.

\section{Flow cytometry}

The intracellular ROS were measured by DHE probes in cells. Cells were seeded in 24-well plates at a density of $6 \times 10^{4}$ cells per well. Serum free DMEM medium was added and exposed to treatments accordingly, followed by PBS wash (twice), as well as DHE and Hoechst incubation for $15 \mathrm{~min}$ at $37^{\circ} \mathrm{C}$. After the reaction, cells were washed twice with PBS and observed using flow cytometry to detect intracellular ROS levels.

\section{Western blotting}

Serum-free DMEM was added to cells and treatments were performed accordingly. The cells were recovered and harvested. Harvested cells were lysed $(20 \mathrm{mM}$ HEPES-OH, pH 7.0; $50 \mathrm{mM} \mathrm{NaCl} ; 10 \%$ glycerol and 0.5\% Triton X 100) and total protein was extracted. Then, proteins were denatured for $5 \mathrm{~min}$, exposed to $12 \%$ sodium dodecyl sulfate-polyacrylamide gel electrophoresis for separation, and transferred into nitrocellulose membranes. Skim milk (5\%) was used to block the membranes for $30 \mathrm{~min}$ at room temperature. They were then incubated with polyclonal rabbit anti-N-cadherin, as well as mouse monoclonal anti-E-cadherin, anti-vimentin, anti-fibronectin, anti-slug, and anti- $\beta$-actin primary antibodies $(1: 1000)$ at $4{ }^{\circ} \mathrm{C}$ overnight. Membranes were washed five times with Tris buffered saline containing Tween (TBST, $150 \mathrm{mM} \mathrm{NaCl}, 10 \mathrm{mM}$ Tris $\mathrm{HCl}$ (pH 7.5) and $0.2 \%$ Tween-20) and were subsequently incubated with horseradish peroxidase-conjugated goat anti-mouse IgG or anti-rabbit IgG for $1 \mathrm{~h}$ at room temperature. After removing excess antibodies by washing with TBST, specific conjugates were detected using a chemiluminescence detection system according to the manufacturer's protocol.

\section{Statistical analysis}

Repeated measures analysis of variance (ANOVA) was used to analyze changes in time and differences between groups for each experiment. Significance was measured using independent-samples t-test. All differences were considered statistically significant if the $\mathrm{p}$-value was less than $0.05(" p<0.05 ; " * p<0.01$; *** $p<0.001)$. All experiments were performed in triplicates.

\section{Results \\ BLM inhibits proliferation and promotes fibrosis in A549 cells}

We constructed a cell model of alveolar epithelial cell fibrosis in vitro and used BLM was to induce the fibrosis of A549 human alveolar epithelial cells. A549 cells were treated with BLM (100 or $200 \mu \mathrm{g} / \mathrm{ml})$ for $48 \mathrm{~h}$. Microscopic observation showed that with the increase in drug concentration, cell fibrosis increased, and the MTT assay showed that cell viability decreased (Fig. 1a, Additional file 1; Fig. S2). Moreover, to detect the change in cell migration upon BLM-induced cell fibrosis, we performed a wound healing assay. Would healing assay showed that the migration of A549 cells was enhanced after treatment with BLM for $48 \mathrm{~h}$ (Fig. 1b, c). Western blotting results showed that expression levels of EMT-related proteins $\mathrm{N}$-cadherin, vimentin, fibronectin, and slug were upregulated, and those of E-cadherin were downregulated. A549 cells developed cellular fibrosis through EMT (Fig. 1dh). These results indicated that BLM inhibited cell proliferation and promoted cell migration and fibrosis in A549 cells.

\section{BLM increases ROS levels and decreases mitochondrial membrane potential in A549 cells}

After treatment of A549 cells with BLM (100 or $200 \mu \mathrm{g} /$ $\mathrm{mL}$ ) for $48 \mathrm{~h}$, fluorescence microscopy showed that the level of intracellular ROS was significantly increased (Fig. 2a), and the same effect was also observed using flow cytometry (Fig. 2b). Fluorescence microscopy also showed that ROS levels in mitochondria increased (Fig. 2c) and the mitochondrial membrane potential 

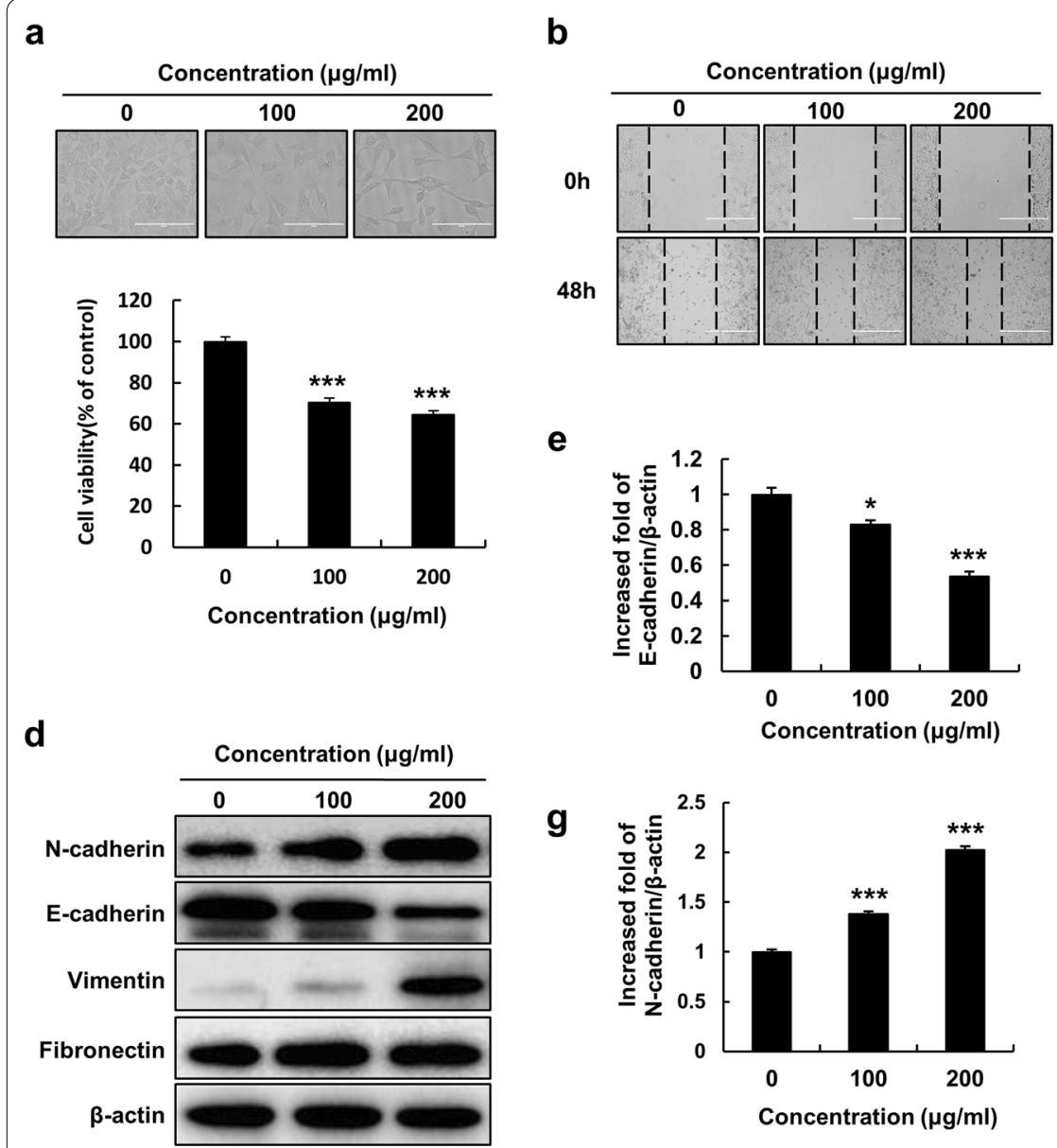

C

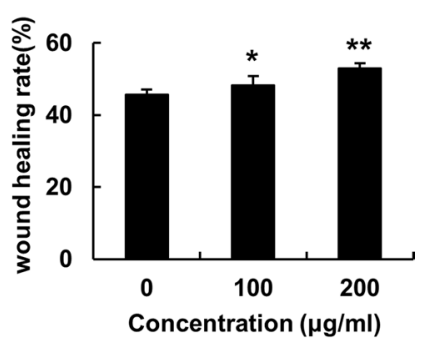

e

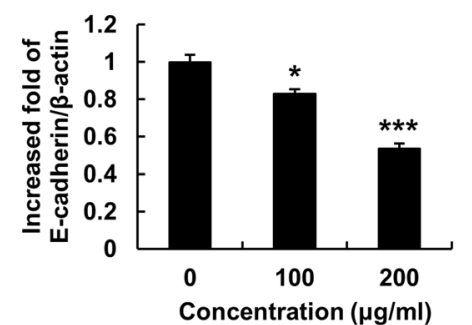

$\mathbf{f}$
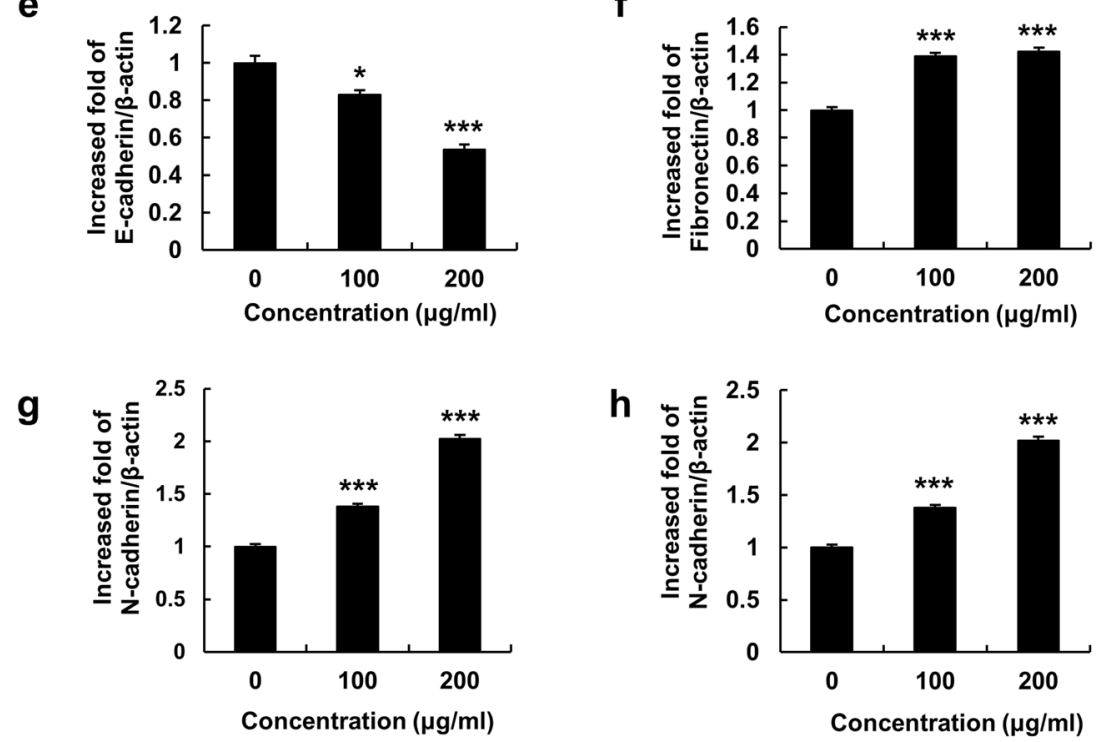

Fig. 1 Bolemycin inhibits the proliferation of A549 cells and promotes fibrosis. a The morphology of cellular fibrosis was observed under the microscope. Cell viability was detected using MTT. b, c Cell migration was detected using would healing assay. $\mathbf{d}$ The expression levels of EMT-related proteins were detected using western blotting. $\mathbf{e}-\mathbf{h}$ The related protein expression levels are represented as the mean \pm standard deviation. Data are presented as the mean \pm standard error of the mean of three different samples. ${ }^{*} P<0.05$, ${ }^{* *} P<0.01$, and ${ }^{* * *} P<0.001$

decreased (Fig. 2d). These results suggested that BLM increased ROS levels and caused mitochondrial dysfunction in A549 cells.

\section{HP inhibits the increase of ROS levels in A549 cells and mitochondria dysfunction induced by BLM}

A549 cells were treated with BLM $(200 \mu \mathrm{g} / \mathrm{mL})$ and HP $(10,20$, and $30 \mu \mathrm{g} / \mathrm{mL})$ for $48 \mathrm{~h}$. Fluorescence microscopy showed that HP significantly inhibited the increase of ROS levels in cells induced by BLM (Fig. 3a). Flow cytometry also showed the same effect (Fig. 3b). At the same time, HP significantly inhibited the increase in ROS levels and the decrease of membrane potential induced by BLM (Fig. 3c, d). These results indicated that HP significantly inhibited the increase in ROS levels and mitochondrial dysfunction induced by BLM in A549 cells.

\section{HP inhibits BLM-induced fibrosis in A549 cells}

Subsequently, we treated A549 cells with BLM $(200 \mu \mathrm{g} /$ $\mathrm{mL})$ and $\mathrm{HP}(10,20$, and $30 \mu \mathrm{g} / \mathrm{mL})$ for $48 \mathrm{~h}$. Microscopic observation showed that HP significantly inhibited BLMinduced cell fibrosis (Fig. 4a). At the same time, MTT assay showed that there was no significant difference in the activity of A549 cells treated with BLM alone or combined with HP for $48 \mathrm{~h}$ (Fig. 4b). Wound healing assay results showed that HP significantly inhibited cell migration induced by BLM (Fig. 4c, d). Western blotting results showed that HP significantly inhibited the changes in the expression levels of EMT-related proteins induced by BLM, thus inhibiting EMT and cell fibrosis of A549 cells (Fig. 4e-i). These results indicated that hispidin significantly inhibited the migration and fibrosis of A549 cells induced by BLM. 
a

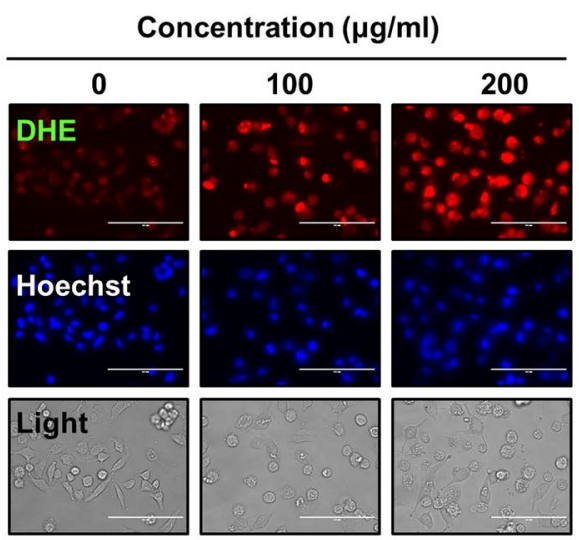

C

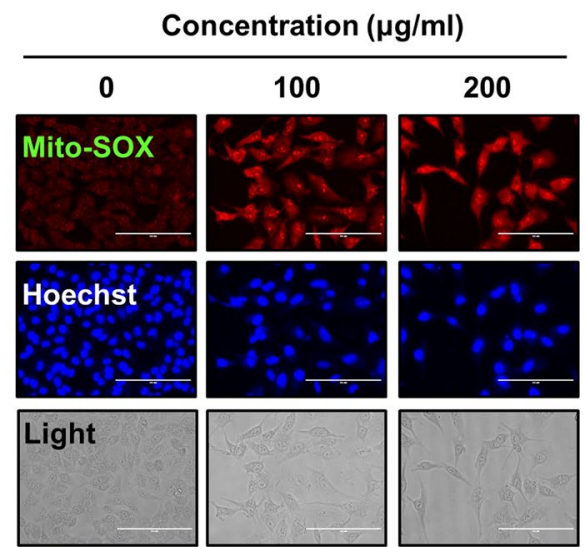

b
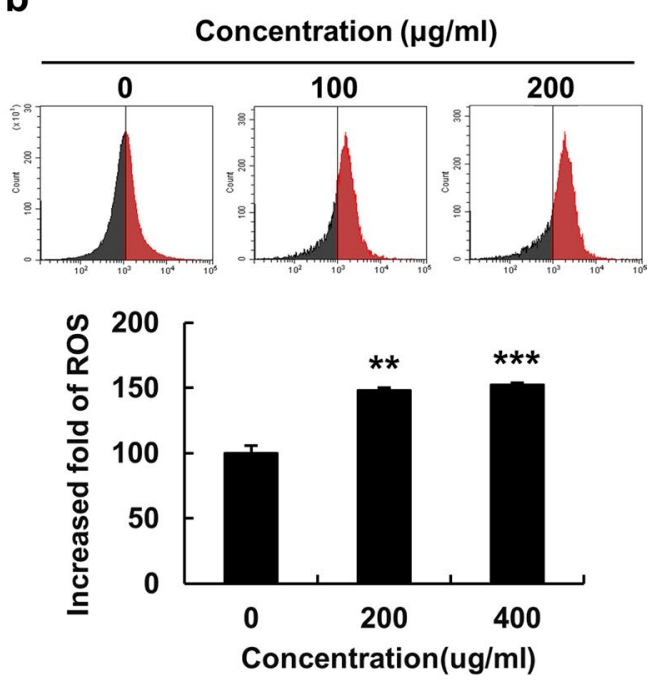

d Concentration $(\mu \mathrm{g} / \mathrm{ml})$

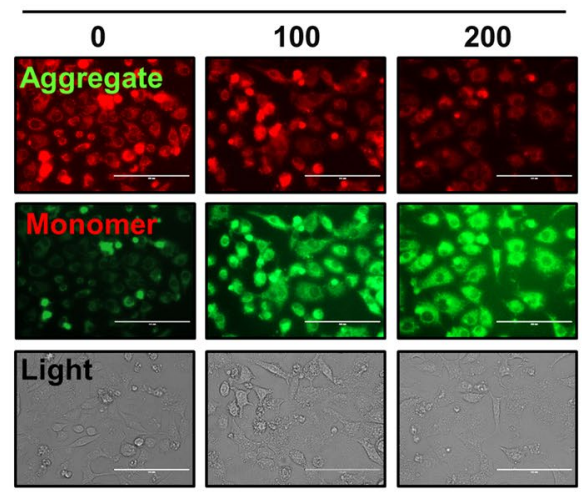

Fig. 2 Bolemycin increased the ROS levels of in A549 cells. a Intracellular ROS levels were detected using flow cytometry, b as well as DHE staining. c ROS levels in mitochondria were detected using Mito-SOX staining. $\mathbf{d}$ The mitochondrial membrane potential was detected using JC-1 staining. ${ }^{*} P<0.01$, and ${ }^{* *} P<0.001$

\section{Discussion}

IPF is a chronic, irreversible and usually fatal lung disease [31], which is highly prevalent in the elderly. Patients with IPF suffer from long-term cough and dyspnea, which is difficult to diagnose, and most patients are already at the advanced stage when they are diagnosed [32]. Today, the prevalence and incidence rate of IPF is increasing [33,34] and the survival time of patients is about 2-3 years after diagnosis [35]. Therefore, there is an urgent need for more effective diagnostic and treatment methods. The specific pathogenesis of the disease is not clear, but more studies have shown that alveolar epithelial type II cells can be used as a driver of idiopathic pulmonary fibrosis [36] and the occurrence of IPF is related to alveolar epithelial cell injury [37] and EMT [38]. Moreover, some researchers also believe that oxidative stress is closely related to pulmonary fibrosis $[37,39]$.

BLM is an antibiotic used to treat various tumors, but it causes severe pneumonia and pulmonary fibrosis [40]. The injury and dysfunction of pulmonary epithelial cells are considered to be an important initial and central process of fibrosis [3], BLM induces the transformation of lung epithelial cells into mesenchymal cells through EMT process, gradually transforms the morphology of lung epithelial cells into mesenchymal phenotype, inhibits the proliferation of epithelial cells and further promotes the process of fibrosis $[3,13,36,38]$. In this study, bleomycin was used to construct the pulmonary fibrosis model. A549 cells were treated with different concentrations of bleomycin for $48 \mathrm{~h}$. The results showed that the cells showed obvious fibrosis at the concentration of $200 \mu \mathrm{g} /$ 


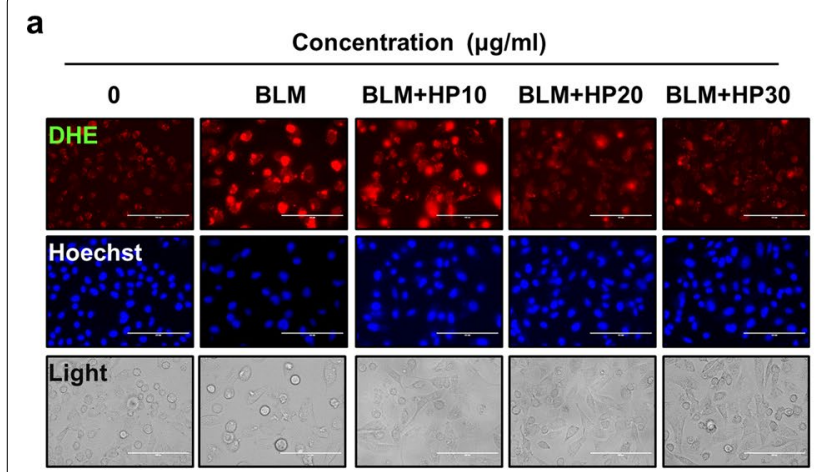

C

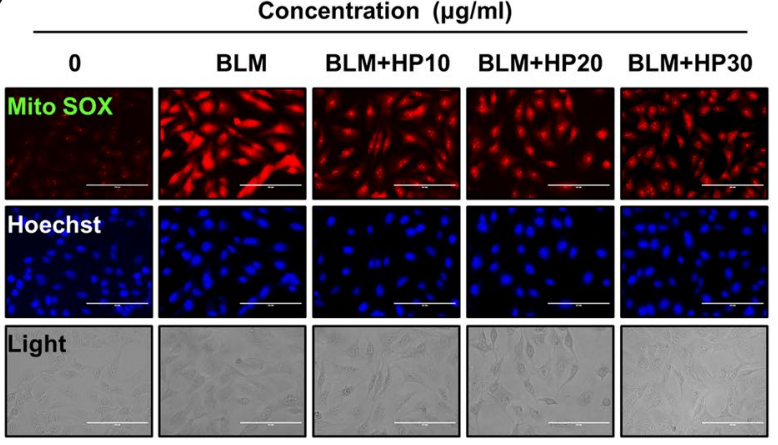

b Concentration $(\mu \mathrm{g} / \mathrm{ml})$

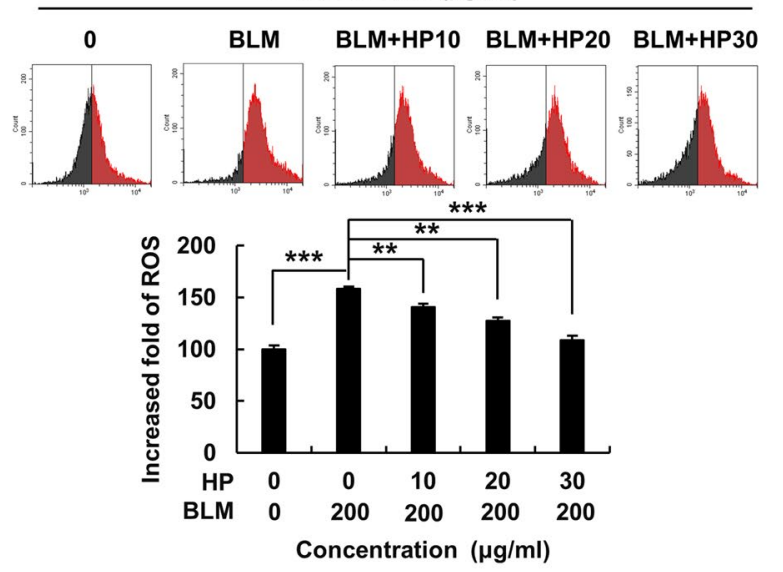

d

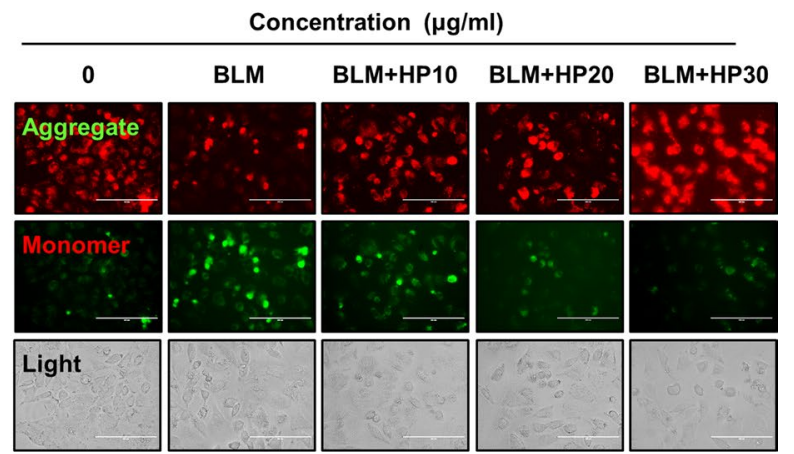

Fig. 3 Hispidin inhibits bolemycin-induced ROS. a Intracellular ROS levels were detected using flow cytometry, b as well as DHE staining. c ROS levels in mitochondria was detected using Mito-SOX staining. $\mathbf{d}$ The mitochondrial membrane potential was detected using JC -1 staining. ${ }^{* *} P<0.01$, and ${ }^{* *} P<0.001$

mL. MTT assay showed that the proliferation of cells was inhibited at $200 \mu \mathrm{g} / \mathrm{mL}$. The EMT related proteins also changed significantly after BLM treatment. Some studies have shown that bleomycin can induce ROS, which may be an important reason for lung epithelial cell injury and EMT transformation [41]. At the same time, mitochondria in cells are the most important position to produce ROS in cells [42], which is closely related to pulmonary fibrosis [43]. Therefore, DHE fluorescent dye detection showed that intracellular ROS increased significantly after BLM treatment, Mito-SOX and JC-1 fluorescent dye detection showed that mitochondrial ROS increased and mitochondria were damaged. Then we focused on $\mathrm{HP}$, which can neutralize free radicals [22]. By further searching the data, we found that HP is a protein kinase $C \beta$ Inhibitors, and protein kinase $C \beta$ overexpression can induce fibrosis in human proximal tubular epithelial cells [44]. We speculate that HP may inhibit cellular fibrosis. After treating fibrotic cells with HP, we found that the level of ROS decreased significantly, fibrotic cell morphology and EMT related proteins were significantly inhibited, it can be seen from the above that HP has a significant inhibitory effect on the fibrosis of A549 alveolar epithelial cells. The specific mechanism has not been explored, but we know that the target signal pathway of HP is TGF- $\beta$ / Smad signal pathway. At the same time, studies have shown that anlotinib attenuates BLM induced pulmonary fibrosis through TGF- $\beta 1$ signaling pathway [45], BLM through TGF- $\beta /$ Smad signaling pathway induces EMT of cultured A549 cells [13], paeoniflorin inhibits TGF- $\beta$ mediated EMT of pulmonary fibrosis through Smad dependent pathway, etc. These reports suggest that TGF- $\beta$ / Smad signaling pathway is closely related to the process of pulmonary fibrosis.

Based on the above information, we speculate that HP may attenuates BLM induced pulmonary fibrosis by TGF- $\beta$ / Smad signaling pathway, which will also become the focus of our next research. This study will also provide new ideas for the treatment of IPF. 


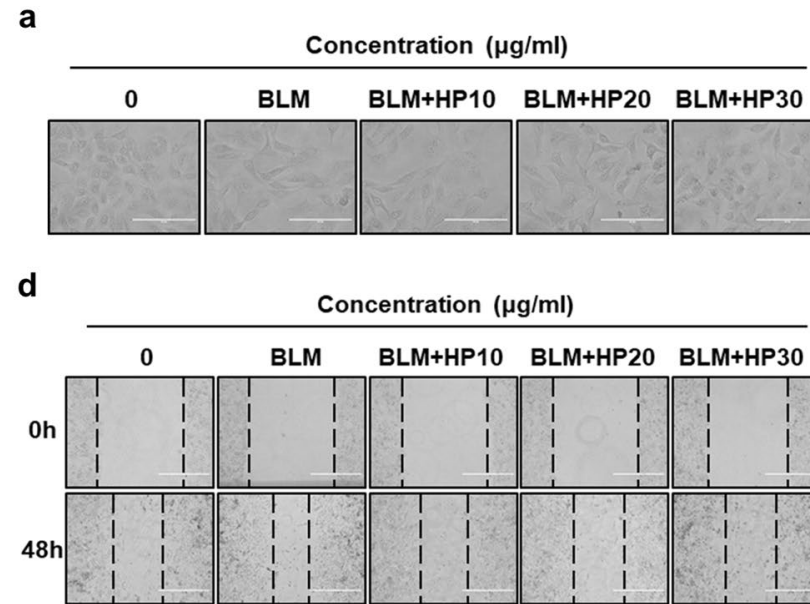

e

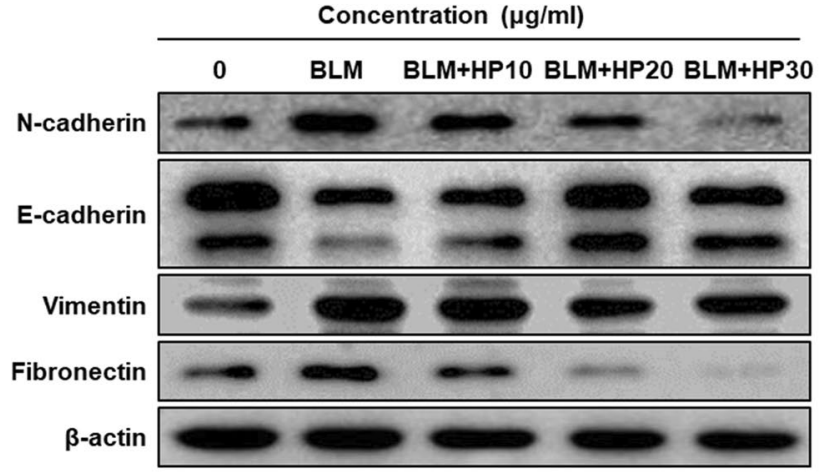

b

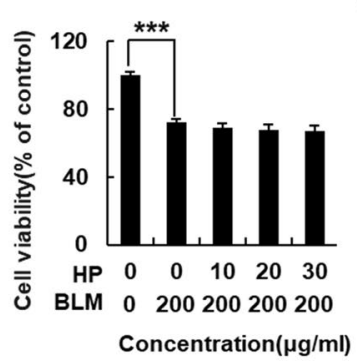

f

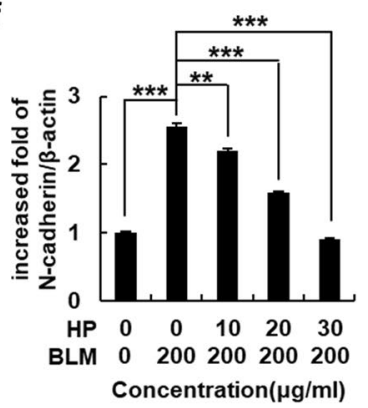

h

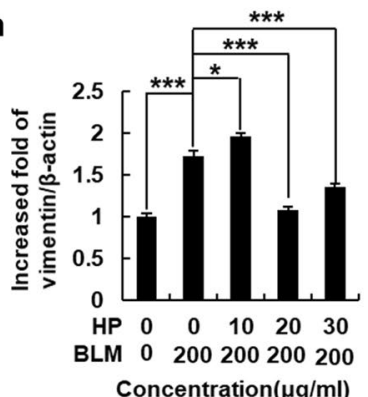

c

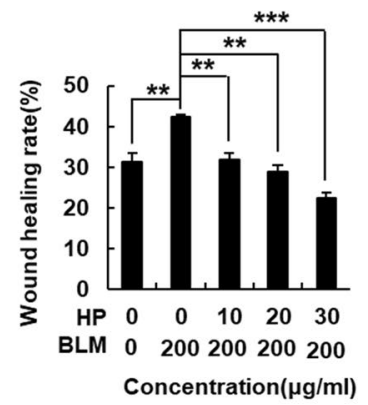

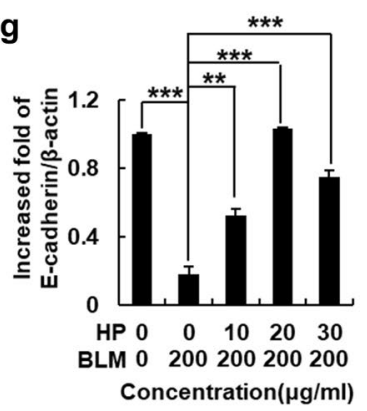

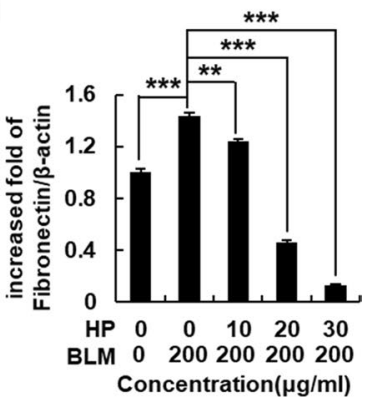

Fig. 4 Effect of Hispidin on bolemycin-induced EMT. a The morphology of cellular fibrosis was observed under the microscope. b Cell viability was detected using MTT. c, d Cell migration was detected using wound healing assay. e Expression levels of EMT-related proteins were detected using western blotting. $\mathbf{f}-\mathbf{i}$ The related protein expression levels were represented as the mean \pm standard deviation. Data are presented as the mean \pm standard error of the mean of three different samples. ${ }^{*} P<0.05,{ }^{* *} P<0.01$, and ${ }^{* *} P<0.001$

\section{Supplementary Information}

The online version contains supplementary material available at https://doi. org/10.1186/s13765-021-00646-X.

Additional file 1: Fig. S1. Cell viability was measured by MTT assay. Cells were treated with different concentrations of hispidin (HP) $(10,20,30$ $\mu \mathrm{g} / \mathrm{mL}$ ) incubated for $48 \mathrm{~h}$. Data are presented as the mean \pm standard error of the mean of three different samples. ${ }^{*} P<0.05$, ${ }^{* *} P<0.01$, and ${ }^{* * *} \mathrm{P}<0.001$. Fig. S2. a The morphology of cellular fibrosis was observed under the microscope. $b$ Intracellular ROS levels were detected using flow cytometry. c, d Cells were treated with different concentrations of Bolemycin (BLM) and hispidin (HP) incubated for $48 \mathrm{~h}$. Data are presented as the mean \pm standard error of the mean of three different samples. ${ }^{*} \mathrm{P}<$ 0.05 , ${ }^{*} P<0.01$, and ${ }^{* * *} P<0.001$

\section{Acknowledgements}

This research was supported by the project of the scientific research team support plan of Heilongjiang Bayi Agricultural University (TDJH201904), China.

\section{Authors' contributions}

CXR, XJ, DXP, HNS and TK performed the experiments and wrote the article. CXR, XJ, DXP, XYG, LYY, YDC, HNS and TK performed the data analysis. YDC, HNS and TK reviewed and edited the manuscript. TK acquired the funding. All authors read and approved the final manuscript.

\section{Funding}

This research was supported by the Basic Science Research Program through the National Research Foundation of Korea funded by the Ministry of Education (2020R111A2052417), The Korean Research Institute of Bioscience and Biotechnology Research Information System (RBM0112112).

\section{Availability of data and materials}

The datasets used and analyzed in this study are available from the corresponding author upon reasonable request.

\section{Declarations}

Competing interests

The authors declare that they have no competing interests. 


\section{Author details}

${ }^{1}$ College of Life Science \& Technology, Heilongjiang Bayi Agricultural University, Xinyanglu, 163319 Daqing, People's Republic of China. ${ }^{2}$ Laboratory Animal Center of Yanbian University, Yanji, Jilin 133002, People's Republic of China. ${ }^{3}$ Primate Resources Center, Korea Research Institute of Bioscience and Biotechnology (KRIBB), 351-33 Neongme-gil, Ibam-myeon, Jeongeup-si, Jeonbuk 56216 , Republic of Korea.

Received: 6 September 2021 Accepted: 20 October 2021 Published online: 28 October 2021

\section{References}

1. Raghu G, Collard HR, Egan JJ, Martinez FJ, Behr J, Brown KK, Colby TV, Cordier JF, Flaherty KR, Lasky JA et al (2011) An official ATS/ERS/JRS/ALAT statement: idiopathic pulmonary fibrosis: evidence-based guidelines for diagnosis and management. Am J Respir Crit Care Med 183(6):788-824

2. Wilson MS, Wynn TA (2009) Pulmonary fibrosis: pathogenesis, etiology and regulation. Mucosal Immunol 2(2):103-121

3. Hewlett JC, Kropski JA, Blackwell TS (2018) Idiopathic pulmonary fibrosis: epithelial-mesenchymal interactions and emerging therapeutic targets. Matrix Biol 71-72:112-127

4. Tatler AL, Jenkins G (2012) TGF- $\beta$ activation and lung fibrosis. Proc Am Thorac Soc 9(3):130-136

5. Cameli P, Carleo A, Bergantini L, Landi C, Prasse A, Bargagli E (2020) Oxidant/antioxidant disequilibrium in idiopathic pulmonary fibrosis pathogenesis. Inflammation 43(1):1-7

6. Wynn TA (2011) Integrating mechanisms of pulmonary fibrosis. J Exp Med 208(7):1339-1350

7. Hilberg O, Simonsen U, du Bois R, Bendstrup E (2012) Pirfenidone: significant treatment effects in idiopathic pulmonary fibrosis. Clin Respir J 6(3):131-143

8. Wollin L, Maillet I, Quesniaux V, Holweg A, Ryffel B (2014) Antifibrotic and anti-inflammatory activity of the tyrosine kinase inhibitor nintedanib in experimental models of lung fibrosis. J Pharmacol Exp Ther 349(2):209-220

9. Liu T, De Los Santos FG, Phan SH (2017) The bleomycin model of pulmonary fibrosis. Methods Mol Biol 1627:27-42

10. Cheresh P, Kim SJ, Tulasiram S, Kamp DW (2013) Oxidative stress and pulmonary fibrosis. Biochim Biophys Acta 1832(7):1028-1040

11. Sleijfer S (2001) Bleomycin-induced pneumonitis. Chest 120(2):617-624

12. Allawzi A, Elajaili H, Redente EF, Nozik-Grayck E (2019) Oxidative toxicology of bleomycin: role of the extracellular redox environment. Curr Opin Toxicol 13:68-73

13. Chen KJ, Li Q, Wen CM, Duan ZX, Zhang JY, Xu C, Wang JM (2016) Bleomycin (BLM) induces epithelial-to-mesenchymal transition in cultured A549 cells via the TGF- $\beta /$ Smad signaling pathway. J Cancer 7(11):1557-1564

14. Tian SL, Yang Y, Liu XL, Xu QB (2018) Emodin attenuates bleomycininduced pulmonary fibrosis via anti-inflammatory and anti-oxidative activities in rats. Med Sci Monit 24:1-10

15. Yan L, Song F, Li H, Li Y, Li J, He QY, Zhang D, Wang F, Zhang M, Zhao $\mathrm{H}$ et al (2018) Submicron emulsion of cinnamaldehyde ameliorates bleomycin-induced idiopathic pulmonary fibrosis via inhibition of inflammation, oxidative stress and epithelial-mesenchymal transition. Biomed Pharmacother 102:765-771

16. Mora AL, Bueno M, Rojas M (2017) Mitochondria in the spotlight of aging and idiopathic pulmonary fibrosis. J Clin Invest 127(2):405-414

17. Radisky DC, Levy DD, Littlepage LE, Liu H, Nelson CM, Fata JE, Leake D, Godden EL, Albertson DG, Nieto MA et al (2005) Rac1b and reactive oxygen species mediate MMP-3-induced EMT and genomic instability. Nature 436(7047):123-127

18. Zhou G, Dada LA, Wu M, Kelly A, Trejo H, Zhou Q, Varga J, Sznajder JI (2009) Hypoxia-induced alveolar epithelial-mesenchymal transition requires mitochondrial ROS and hypoxia-inducible factor 1. Am J Physiol Lung Cell Mol Physiol 297(6):L1120-1130

19. Shao HJ, Jeong JB, Kim KJ, Lee SH (2015) Anti-inflammatory activity of mushroom-derived hispidin through blocking of NF-kB activation. J Sci Food Agric 95(12):2482-2486
20. Han JJ, Bao L, He LW, Zhang XQ, Yang XL, Li SJ, Yao YJ, Liu HW (2013) Phaeolschidins A-E, five hispidin derivatives with antioxidant activity from the fruiting body of Phaeolus schweinitzii collected in the Tibetan Plateau. J Nat Prod 76(8):1448-1453

21. Chandimali N, Huynh DL, Jin WY, Kwon T (2018) Combination effects of hispidin and gemcitabine via inhibition of stemness in pancreatic cancer stem cells. Anticancer Res 38(7):3967-3975

22. El Hassane A, Shah SA, Hassan NB, El Moussaoui N, Ahmad R, Zulkefeli M, Weber JF (2014) Antioxidant activity of hispidin oligomers from medicinal fungi: a DFT study. Molecules 19(3):3489-3507

23. Lv LX, Zhou ZX, Zhou Z, Zhang $L$, Yan R, Zhao Z, Yang LY, Bian XY, Jiang HY, Li YD et al (2017) Hispidin induces autophagic and necrotic death in SGC-7901 gastric cancer cells through lysosomal membrane permeabilization by inhibiting tubulin polymerization. Oncotarget 8(16):26992-27006

24. Kim DE, Kim B, Shin HS, Kwon HJ, Park ES (2014) The protective effect of hispidin against hydrogen peroxide-induced apoptosis in $\mathrm{H} 9 \mathrm{c} 2$ cardiomyoblast cells through Akt/GSK-3 $\beta$ and ERK1/2 signaling pathway. Exp Cell Res 327(2):264-275

25. Han $Y-H$, Chen D-Q, Jin M-H, Jin Y-H, Li J, Shen G-N, Li W-L, Gong Y-X, Mao Y-Y, Xie D-P et al (2020) Anti-inflammatory effect of hispidin on LPS induced macrophage inflammation through MAPK and JAK1/STAT3 signaling pathways. Appl Biol Chem 63(1):21

26. Lim JH, Lee YM, Park SR, Kim DH, Lim BO (2014) Anticancer activity of hispidin via reactive oxygen species-mediated apoptosis in colon cancer cells. Anticancer Res 34(8):4087-4093

27. Lee JH, Lee JS, Kim YR, Jung WC, Lee KE, Lee SY, Hong EK (2011) Hispidin isolated from Phellinus linteus protects against hydrogen peroxideinduced oxidative stress in pancreatic MIN6N $\beta$-cells. J Med Food 14(11):1431-1438

28. Park JM, Lee JS, Song JE, Sim YC, Ha SJ, Hong EK (2015) Cytoprotective effect of hispidin against palmitate-induced lipotoxicity in C2C12 myotubes. Molecules 20(4):5456-5467

29. Chen W, Shen Y, Su H, Zheng X (2014) Hispidin derived from Phellinus linteus affords protection against acrylamide-induced oxidative stress in Caco- 2 cells. Chem Biol Interact 219:83-89

30. Huang SY, Chang SF, Chau SF, Chiu SC (2019) The protective effect of hispidin against hydrogen peroxide-induced oxidative stress in ARPE-19 cells via Nrf2 signaling pathway. Biomolecules 9(8):380

31. Liang Q, Cai W, Zhao Y, Xu H, Tang H, Chen D, Qian F, Sun L (2020) Lycorine ameliorates bleomycin-induced pulmonary fibrosis via inhibiting NLRP3 inflammasome activation and pyroptosis. Pharmacol Res 158:104884

32. Zaman T, Lee JS (2018) Risk factors for the development of idiopathic pulmonary fibrosis: a review. Curr Pulmonol Rep 7(4):118-125

33. Hutchinson J, Fogarty A, Hubbard R, McKeever T (2015) Global incidence and mortality of idiopathic pulmonary fibrosis: a systematic review. Eur Respir J 46(3):795-806

34. Hutchinson JP, McKeever TM, Fogarty AW, Navaratnam V, Hubbard RB (2014) Increasing global mortality from idiopathic pulmonary fibrosis in the twenty-first century. Ann Am Thorac Soc 11(8):1176-1185

35. Bringardner BD, Baran CP, Eubank TD, Marsh CB (2008) The role of inflammation in the pathogenesis of idiopathic pulmonary fibrosis. Antioxid Redox Signal 10(2):287-301

36. Parimon T, Yao C, Stripp BR, Noble PW, Chen P (2020) Alveolar epithelial type II cells as drivers of lung fibrosis in idiopathic pulmonary fibrosis. Int J Mol Sci 21(7):2269

37. Richeldi L, Collard HR, Jones MG (2017) Idiopathic pulmonary fibrosis. Lancet 389(10082):1941-1952

38. Tian R, Zhu Y, Yao J, Meng X, Wang J, Xie H, Wang R (2017) NLRP3 participates in the regulation of EMT in bleomycin-induced pulmonary fibrosis. Exp Cell Res 357(2):328-334

39. Noble PW (2006) Idiopathic pulmonary fibrosis: natural history and prognosis. Clin Chest Med 27(1 Suppl 1):S11-16, v

40. Song N, Liu J, Shaheen S, Du L, Proctor M, Roman J, Yu J (2015) Vagotomy attenuates bleomycin-induced pulmonary fibrosis in mice. Sci Rep 5:13419

41. Muthuramalingam K, Cho M, Kim Y (2020) Cellular senescence and EMT crosstalk in bleomycin-induced pathogenesis of pulmonary fibrosis-an in vitro analysis. Cell Biol Int 44(2):477-487 
42. Gorman GS, Chinnery PF, DiMauro S, Hirano M, Koga Y, McFarland R, Suomalainen A, Thorburn DR, Zeviani M, Turnbull DM (2016) Mitochondrial diseases. Nat Rev Dis Primers 2:16080

43. Malsin ES, Kamp DW (2018) The mitochondria in lung fibrosis: friend or foe? Transl Res 202:1-23

44. Slattery C, Ryan MP, McMorrow T (2008) Protein kinase C beta overexpression induces fibrotic effects in human proximal tubular epithelial cells. Int J Biochem Cell Biol 40(10):2218-2229

45. Ruan H, Lv Z, Liu S, Zhang L, Huang K, Gao S, Gan W, Liu X, Zhang S, Helian Ket al (2020) Anlotinib attenuated bleomycin-induced pulmonary fibrosis via the TGF- $\beta 1$ signalling pathway. J Pharm Pharmacol 72(1):44-55

\section{Publisher's Note}

Springer Nature remains neutral with regard to jurisdictional claims in published maps and institutional affiliations.

\section{Submit your manuscript to a SpringerOpen ${ }^{\circ}$ journal and benefit from:}

- Convenient online submission

- Rigorous peer review

- Open access: articles freely available online

- High visibility within the field

- Retaining the copyright to your article

Submit your next manuscript at $\gg$ springeropen.com 